\title{
e-interview
}

columns

\section{Janet Treasure}

Janet Treasure is Professor of Psychiatry at King's College London and Head of the Eating Disorders Unit at the South London and Maudsley NHS Trust. She trained at the Maudsley Hospital. Her special interests include eating disorders.

\section{Is there any aspect of work that} induces procrastination?

I cringe when I get rejections and hide the reports on a pile. I rely on other team members to make a start with the riposte and then I rejoin the process.

Psychotherapy or psychobabble? Psychotherapy skills are core aspects of being a psychiatrist. The essential elements are being able to develop a good balanced alliance, understanding how to work with people who are poorly motivated to change, having knowledge of the skills required for behaviour change (e.g. medication adherence, eating, etc) and being able to implement them, and finally being able to work with families in order to help them develop these skills.

\section{Should wards be single or mixed gender?}

In our case we occasionally have a single man with our 17 females. They can get quite lonely. We are less good than I would like at making our information gender neutral. This can make males in our system feel even more alienated. However, despite these problems I think that the specialised skills of our nursing team working within a group context are essential for change and that this resource should be available across gender and age range.

\section{Is psychiatry a thankless task?}

You have to be patient as sometimes the thanks are delayed. For example, recently I was thanked for life-saving treatment I gave 24 years ago when I was a senior house officer on the eating disorder unit. The individual contacted me as I had been on Woman's Hour and she told me she was now a professor. If you want more instant gratification I would recommend working with carers. We run workshops for carers (usually parents) of people with eating disorders in order to teach them how best to manage and motivate their affected offspring. These are highly rewarding. They can be fun and the parents are extremely grateful.

\section{Why do you enjoy research?}

I guess I have a strong novelty-seeking trait. The iterative process of discovering the deeper understanding of the mechanisms, translating that into meaning for clinical practice and then implementing that into treatment is wonderfully sustaining. Clinically linked research such as this is the lifeblood of medicine. However, the current bureaucratic bottlenecks threaten this

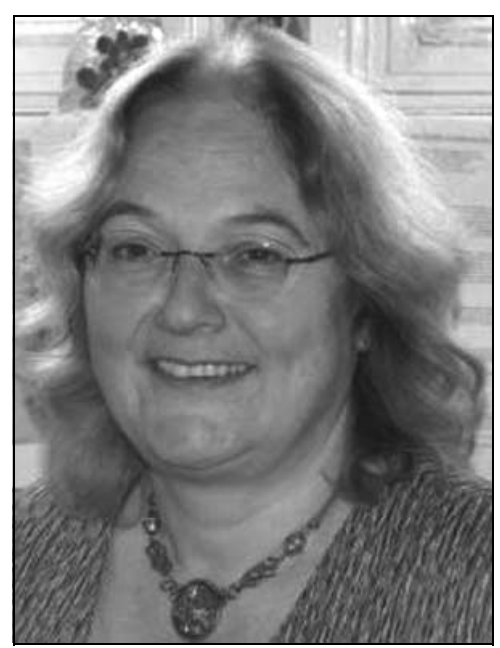

process. I find it is essential to work within a team as the research process requires the strengths and skills of many personality types. I think therefore that the move to provide an overarching team such as the Mental Health Research Network is essential in order to plug gaps and attend to the need for an eye and heart able to cope with the detail of the logistic hurdles of a multiplicity of health systems we now have to contend with

\section{How competitive are you?}

I guess our patient group are a salutary reminder of the toxicity of competition and striving for perfection. I hope that I learn from working with them to moderate any such tendency in myself.

\section{Do you think the MRCPsych exam should be phased out?}

I find the objective structured clinical exams (OSCEs) are an interesting test of clinical skills. However, they could be shorter and used as an opportunity to give more feedback to the individual. The resource of the actor and examiner seems under-used when we just give $1-5$ ratings. There is no doubt that being able to see ourselves as others see us is as much a gift as a shock. A psychologist on our team came up to me the other day and said he had found it useful to use training tapes I had done 5 years and then 1 year ago and have the course participants rate my performance. He told me that they judged me to have improved! I think this illustrates how important teaching and training is to keep our skills on top form.

\section{Why don't medical students aspire to be psychiatrists?}

How true is this? I think looking between schools to see what environment shapes a higher take up of psychiatry would be informative. I find teaching medical students such a privilege. They are a joy to work with. I do a short module on motivational interviewing which illustrates how psychotherapy skills and hopefully a psychiatric context can inform all branches of medicine.
Is there an argument for psychiatrists having individual psychotherapy? I would prefer for people to be exposed to a broad church of styles. Signing up to one approach by investing a great deal of time and effort is worrisome to me. In many of the shorter psychotherapies (e.g. cognitive-behavioural therapy (CBT), motivational interviewing) much of the training involves practice, i.e. role-playing of real life issues, and that seems to be necessary and may be even sufficient to attain psychotherapy skills.

\section{Do you have a mentor?}

In hindsight I did have one, Gerald Russell, although neither of us would have called it this. Now I have a great colleague. I went on the NHS mentoring course offered by SE Thames. It was run by a business enterprise that consulted with business, the BBC etc. It was rather like teaching grandmother to suck eggs. However, observing the process was interesting. It consisted of teaching the skills of motivational interviewing and CBT with some attention to how past learning experiences inform the current context. I learnt from it that it was possible to teach these skills to people who did not have a wealth of theoretical background or experience. This gave me more confidence to teach such skills to our carers. We frame the workshops as enabling them to develop the skills to be expert carers so that they can mentor or coach their daughter through her illness. Some carers are now being trained in the advanced skills of motivational intervening in a course that we run and they will join us in running the workshops. We hope that this will disseminate skills widely. I think this is the way that the expert patient concept can be applied in the context of psychiatry.

\section{Is there a recurrent ethical dilemma} that stalls you?

We occasionally have the problem of what to do when an individual says she does not want her family involved. We usually find that with persistence and clarity about what we want to achieve we can get over that hurdle. Our most difficult case was a 17-year-old girl with anorexia nervosa and obsessive-compulsive disorder. At her previous hospital she had said she did not want to see her parents. The hospital complied with her wishes and banned the parents from entering the ward. The parents later told us how they would walk around the perimeter of the hospital feeling hopeless. I went with my gut feeling and did not get preoccupied with legal niceties. We set gradually increasing goals to start some communication by e-mail, phone and then phone calls from adjoining rooms, until we were able to do our usual family work.

Lucy Watkin 